\title{
Two Hypotheses on the Aetiology of Response of Plants to Phytopathogenic Bacteria
}

\author{
By G. L. ERCOLANI \\ Istituto di Patologia Vegetale, Università degli Studi di Bari, Italy* \\ Stazione Sperimentale per l'Industria delle Conserve Alimentari in Parma, Italy'
}

(Received 3 August 1972)

\begin{abstract}
SUMMARY
Graded doses of six phytopathogenic bacteria, namely Pseudomonas lachrymans, $P$. morsprunorum, $P$. phaseolicola, $P$. syringae, $P$. tabaci and $P$. tomato, were introduced into the leaves of one of their natural (homologous) hosts and of other (heterologous) plants. Probit slopes for the infectivity of any of the six bacteria did not exceed the value $b=2$ in the homologous combinations, but were much greater than 2 in the heterologous ones. In the homologous combinations, the mean probability, $P$, per inoculated bacterium of multiplying to induce host response was invariant to inoculum dose, $d$. Hence the probability, $Q$, that a host would not respond after inoculation with $d$ bacteria was given by the simple exponential, $Q=e^{-P d}$. In the heterologous combinations, the value of $P$ increased with increasing $d$.

When a streptomycin-sensitive and a streptomycin-resistant variant of the same bacterium were mixed together in a $\mathrm{I}: \mathrm{I}$ proportion in the challenge dose, plants responding after inoculation with a heterologous pathogen yielded a mixture of both variants in the same proportion, whereas those responding to inoculation with a homologous pathogen yielded either a I : I mixture of both variants or a large predominance of a single variant, depending on whether the dose contained more or less than I ED 50. It was concluded from these experiments that the relationships between inoculated cells of homologous and heterologous bacteria during growth in vivo were described best by the hypothesis of independent action and the hypothesis of co-operative action, respectively.
\end{abstract}

\section{INTRODUCTION}

The definitions of host range and host specificity, as applied to phytopathogenic bacteria, have been open to many questions following repeated demonstrations that these bacteria, when inoculated under suitable conditions, are able to multiply and induce symptoms not only in their natural (homologous) hosts, but also in quite unrelated (heterologous) plants (Klement \& Lovrekovich, I96I, I962; Klement, Farkas \& Lovrekovich, 1964; Ercolani \& Crosse, 1966). Differences have been established in the pattern of growth in vivo and the mechanism of induction of symptoms between homologous and heterologous combinations (Ercolani \& Crosse, 1966; Klement \& Goodman, I967a), but the relationships between growth data and dose/response data in different systems have not received adequate attention.

Many plants respond predictably with visible symptoms after inoculation with phytopathogenic bacteria only when the challenge dose contains more than one bacterial cell. Therefore the response observable in such plants might be assumed to be the result of either (i) the action of one random inoculated bacterium which chances to generate a large enough

* Present address. 
progeny in vivo to cause infection, or (ii) the joint action of several inoculated bacteria, all of which contribute to overcome plant defences. Possibilities (i) and (ii) are the basic postulates of two well-known models of infection, i.e. the hypothesis of independent action and the hypothesis of co-operative action, respectively (Meynell \& Stocker, I957). The results of most titration experiments on animals suggest that living micro-organisms are independent after inoculation, whereas co-operation occurs between drug molecules in vivo (see Meynell, 1957; Meynell \& Meynell, 1970). Comparable information is lacking for plants. However, Corynebacterium michiganense and Erwinia carotovora have been reported to act independently during infection of tomato plants and invasion of potato tuber discs respectively (Ercolani, 1967a, $b$; Pérombelon, 197I).

This paper describes the application of the hypothesis of independent action and the hypothesis of co-operative action to the aetiology of response of some plants to homologous and heterologous phytopathogenic Pseudomonas spp. A preliminary proposal for the applicability of the two hypotheses has been advanced (Ercolani, I968a).

\section{METHODS}

Test plants. These were plants of bean (Phaseolus vulgaris) 'Borlotto di Vigevano', sweet cherry (Prunus avium) 'Bigarreau Moreau', cucumber (Cucumis sativus) 'SMR I8', pear (Pyrus communis) 'Kaiser', tobacco (Nicotiana tabacum) 'Burley Ky I6', and tomato (Lycopersicon esculentum) 'Ace'. Bean, cucumber, tobacco and tomato plants were raised from surface-sterilized seed sown in Vermiculite, transplanted individually at the seedling stage into pots of coarse silica sand, and grown in a room with 50 to $60 \%$ r.h., 20000 lux provided by fluorescent daylight lamps (Osram-L 40 W/20 R and $40 \mathrm{~W} / \mathrm{I} 5 \mathrm{R}$ ) for a I 2-h photoperiod, day temperature of $23 \pm 2{ }^{\circ} \mathrm{C}$ and night temperature of $16 \pm 2{ }^{\circ} \mathrm{C}$. To prepare cherry and pear plant material, cuttings of either species, which had just completely rooted under mist, were obtained from a commercial nursery, transplanted individually into pots of coarse silica sand, and grown further in a greenhouse with 70 to $80 \%$ r.h., approximately 10000 lux on a 12 -h photoperiod in addition to sunlight, and a temperature of $24 \pm 4{ }^{\circ} \mathrm{C}$ during the day and $16 \pm 3{ }^{\circ} \mathrm{C}$ at night. After transplanting, all plants were watered daily with the nutrient solution of Hoagland \& Snyder (1933) and grown for definite periods before they were used in inoculation experiments: 2 weeks for the beans, 4 weeks for the cucumbers and the tomatoes, 6 weeks for the tobacco plants, and 8 weeks for the cherries and the pears. To ensure that the plants did not harbour any unwanted micro-organisms, random samples were taken periodically and plated on nutrient agar containing $5 \%$ sucrose (NAS), on which all bacteria included in this study (see next paragraph) form characteristic colonies (Crosse, I959; Lelliott, Billing \& Hayward, 1966).

Bacterial cultures. The following cultures, representative of six fluorescent phytopathogenic Pseudomonas nomenspecies, were used initially: P. lachrymans NCPPBI425, isolated originally by $Z$. Klement from cucumber in Hungary in $\mathrm{I} 958 ; P$. morsprunorum $\mathrm{CM} 8$, isolated from necrotic leaf spots on sweet cherry trees near Bologna, Italy, in 1965; P. phaseolicola IL3, from halo blight lesions on dwarf bean plants 'Borlotto di Vigevano' near Bologna, Italy, in $1962 ; P$. syringae SB4, from blighted blossoms on pear trees 'Kaiser' near Modena, Italy, in $1965 ; P$. tabaci TL2, from wildfire lesions on the leaves of tobacco plants 'Burley Ky I6' near Piacenza, Italy, in $1965 ; P$. tomato PT4, from tomato fruits affected with bacterial speck at Parma, Italy, in 1965.

A streptomycin-sensitive clone $\left(\mathrm{Sm}^{\mathrm{s}}\right)$ and a streptomycin-resistant, non-streptomycindependent clone $\left(\mathrm{Sm}^{\mathrm{r}}\right)$ of each culture were used in the experiments described below. The 
$\mathrm{Sm}^{\mathrm{s}}$ clones were isolated at the beginning of the work from discrete lesions produced by inoculating each of the original cultures on the leaves of its homologous host. The $\mathrm{Sm}^{\mathrm{r}}$ clones were selected by plating thick suspensions of $\mathrm{Sm}^{\mathrm{s}}$ bacteria on plates of nutrient agar (NA) containing $400 \mu \mathrm{g}$ streptomycin $/ \mathrm{ml}$. All cultures were maintained on nutrient agar + $2 \%$ glycerol (NAG) slopes in screw-capped vaccine bottles and stored at $4{ }^{\circ} \mathrm{C}$.

$\mathrm{Sm}^{\mathrm{s}}$ and $\mathrm{Sm}^{\mathrm{r}}$ variants of each bacterium had the same growth rate in vitro and in vivo, and did not affect each other's specific growth rate when they were cultured together. The ED 50s (see below) of the variants of each pathogen for the homologous host did not differ significantly.

Preparation of inocula. Exponentially growing cultures were prepared by subculturing the bacteria on fresh NAG slopes twice at daily intervals and incubating at $25^{\circ} \mathrm{C}$. The $24 \mathrm{~h}$ growth from the second slope was quickly suspended in sterile distilled water (SDW), washed by centrifuging and resuspending twice in SDW, and finally adjusted nephelometrically to a concentration of $10^{8}$ viable bacteria $/ \mathrm{ml}$ by reference to a calibration curve relating scattered light to viable cell counts. The stock suspensions thus prepared were rapidly diluted with SDW to the required concentration, and the resulting suspensions were used immediately to challenge the plants according to the techniques described below.

In the experiments designed to determine dose/response relationships, the doses of inoculum were equally spaced by a dilution factor of either $10^{-0.5}$ (in host/pathogen combinations of the homologous type) or $\mathrm{I}^{-\mathbf{0 . 2}}$ (in heterologous combinations) between an upper and lower limit corresponding to an expected response of approximately 0.9 and 0.1 as indicated by pilot experiments. In the experiments intended to determine the composition of bacterial populations in plants responding to inoculation, equal volumes of two suspensions containing an estimated concentration of $10^{8}$ viable cells $/ \mathrm{ml}$ of either the $\mathrm{Sm}^{\mathrm{s}}$ or the $\mathrm{Sm}^{\mathrm{r}}$ variant were mixed together and then diluted to give a number of selected doses. Plate counts were always made to determine the exact composition of all suspensions. In the experiments with mixtures of $\mathrm{Sm}^{\mathrm{s}}$ and $\mathrm{Sm}^{\mathrm{r}}$ bacteria, doses were expressed as number of ED 50s (see below), the latter being computed on the summed results of the experiments reported in Table I. Pilot experiments indicated that the ED 50 of a I : I mixture of $\mathrm{Sm}^{\mathrm{s}}$ and $\mathrm{Sm}^{\mathrm{r}}$ variants of the same pathogen did not differ from that of either variant alone.

Inoculation techniques. Each plant was enclosed in a plastic bag, uncovered after $4 \mathrm{~h}$ and inoculated immediately as described by Ercolani \& Crosse (1966). Bacterial suspensions were applied to the fifth lowest leaf of the plants, with the exception of the beans which were inoculated on the lowest trifoliate leaf, and cucumbers which were challenged on the third lowest true leaf. In infectivity titration experiments, each concentration of inoculum was administered to a separate group of 30 plants. In other experiments with mixtures of $\mathrm{Sm}^{8}$ and $\mathrm{Sm}^{\mathrm{r}}$ bacteria, plants were inoculated in groups of 10 or 20 to each dose level, depending on whether the challenge dose contained more or less than I ED 50 (see below).

Inoculation procedures were standardized to ensure that leaves of comparable size were inoculated on each plant, and that each leaf was infiltrated uniformly with bacterial suspensions. Calibration experiments with suspensions containing $10^{3}, 10^{5}$ and $10^{7}$ bacteria $/ \mathrm{ml}$, using the homologous pathogen, showed (i) that the mean inoculum dose, i.e. the mean number of bacteria introduced into each leaf, was in all three dose groups a constant fraction of the number of bacteria $/ \mathrm{ml}$ of inoculum, namely 0.104 of that number in pear, 0.126 in cherry, 0.313 in bean, 0.590 in tomato, 0.802 in cucumber, and 0.920 in tobacco leaves; and (ii) that within each dose group, the range of individual inoculum doses introduced into the leaves of any one plant species was invariably narrower than the $95 \%$ confidence limits of the number of bacteria in the corresponding mean inoculum dose as estimated by the 
method of Seligman \& Mickey (I964) using a dilution factor of $10^{-\frac{1}{3}}$ and inoculating 20 tubes at each dilution level. Based on these results, all leaves of any one plant species in any one dose group were considered for practical purposes to have received an equal dose of inoculum, the size of which was computed directly from the known concentration of inoculum by using the fractional factors given above.

Response records. Quantal responses only were taken by recording the number of inoculated healthy and diseased leaves daily up to 20 days after challenge. Water-soaking of infected tissues, gradually followed by typical field symptoms, were observed only in homologous combinations. Symptoms induced by heterologous bacteria consisted of the sudden appearance of dry necrotic areas, suggestive of a hypersensitive plant reaction (Klement \& Goodman, 1967a).

Determination of dose/response relationships. Plant response records were subjected separately for each infection experiment to probit analysis (Finney, 197I). The median effective dose (ED 50) and the slope of the log dose/probit response curve (b) were estimated by maximizing the likelihood functions, and the precision of the estimates was determined by using the variance formulae.

Determination of bacterial clones in plants responding. This was done in the inoculation experiments with mixtures of $\mathrm{Sm}^{\mathrm{s}}$ and $\mathrm{Sm}^{\mathrm{r}}$ variants. As soon as any leaf responded, it was cut away $\mathrm{I} \mathrm{cm}$ from the stem, surface-sterilized for $4 \mathrm{~min}$ in a $2 \%(\mathrm{w} / \mathrm{v})$ aqueous solution of chloramine $\mathrm{T}$ containing $0.0 \mathrm{I} \%$ sodium sulphosuccinate as wetting agent, washed in running water and three changes of SDW, blotted dry, suspended in $10 \mathrm{ml}$ of sterile $0.05 \mathrm{M}$ -

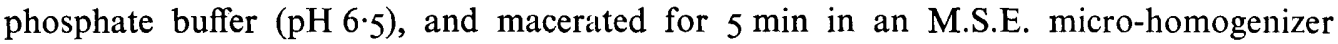
running at $\mathrm{I} 2000 \mathrm{rev}$. $/ \mathrm{min}$. The homogenate was held for approximately $\mathrm{I} \mathrm{h}$ at room temperature with periodical shaking before making tenfold dilutions, each of which was spread in $0.1 \mathrm{ml}$ amounts on the surface of five NAS plates. Plates developing 20 to 200 colonies after 4 days at $25^{\circ} \mathrm{C}$ were replicated with a velvet pad (Lederberg \& Lederberg, 1952) on the surface of a plate of plain NA and a plate of NA containing $400 \mu \mathrm{g}$ streptomycin $/ \mathrm{ml}$. Between 234 and 680 colonies were scored as $\mathrm{Sm}^{\mathrm{g}}$ or $\mathrm{Sm}^{\mathrm{r}}$ for each inoculation experiment.

From 12 plants found to contain either variant alone, one $\mathrm{Sm}^{\mathrm{s}}$ and one $\mathrm{Sm}^{\mathrm{r}}$ clone of each pathogen were isolated and re-examined for their growth rate in vitro and in vivo, their ED 50 for the homologous host, and their effect on the specific growth rate of the other variant in mixed culture. No differences could thus be detected between these re-isolates and the original cultures.

\section{RESULTS}

Infectivity titration experiments. The results of the probit analysis of plant response records are shown in Table $\mathrm{I}$. The data for the heterologous combinations are based on the results obtained with all dose groups, whereas only the results recorded for those dose groups which gave a response of between 0.3 and 0.7 are incorporated in the figures given for the homologous combinations. When more extreme responses were included in the analysis for the homologous combinations, the upper and lower branches of the resulting probit diagrams showed an upward bias so that the log dose/probit response relationship assumed a distinctly curvilinear trend. However, an excellent fit of a straight line to the complete set of experimental data for both the heterologous and the homologous combinations was obtained when $\log (-\ln$ response) was plotted versus $\log$ dose, as, for instance, in the so-called Weibull analysis (Peto, 1953; Armitage, 1959; Shortley \& Wilkins, 1965).

In all plant/pathogen combinations the ED 50 values of the homologous bacteria were at least roo-fold lower than those of the heterologous ones. However, an accurate estimate of 
Table I. Dose/response relationships observed in infectivity titration experiments

\begin{tabular}{|c|c|c|c|c|c|}
\hline Pathogen & Host & $\begin{array}{l}\text { Combination } \\
\text { type }\end{array}$ & $\begin{array}{l}\text { Expt } \\
\text { no. }\end{array}$ & $\log \mathrm{ED}_{50}$ & $b$ \\
\hline \multirow{5}{*}{$\begin{array}{l}\text { Pseudomonas lachrymans } \\
\quad\left(\mathrm{Sm}^{\mathrm{s}}\right)\end{array}$} & Cucumber & Homologous & I & $\mathrm{I} \cdot 88 \mathrm{I} \pm 0.295$ & $1 \cdot 943 \pm 0.104$ \\
\hline & & & 2 & $\mathrm{I} \cdot 92 \mathrm{I} \pm 0.295$ & $\mathrm{I} \cdot 872 \pm 0.093$ \\
\hline & & & 3 & $1 \cdot 785 \pm 0.301$ & $2.001 \pm 0.101$ \\
\hline & Tobacco & Heterologous & $\mathbf{I}$ & $4 \cdot 740 \pm 0 \cdot 324$ & $12 \cdot 242 \pm 2 \cdot 318$ \\
\hline & & & 2 & $4 \cdot 77 \mathrm{I} \pm 0.312$ & $14 \cdot 245 \pm 2 \cdot 849$ \\
\hline \multirow[t]{2}{*}{ P. lachrymans $\left(\mathrm{Sm}^{\mathrm{r}}\right)$} & Cucumber & Homologous & I & $1.854 \pm 0.305$ & $I \cdot 904 \pm 0.09 I$ \\
\hline & Tobacco & Heterologous & $\mathbf{I}$ & $4.785 \pm 0.288$ & $11 \cdot 982 \pm 2 \cdot 702$ \\
\hline \multirow[t]{4}{*}{ P. morsprunorum $\left(\mathrm{Sm}^{\S}\right)$} & Cherry & Homologous & 1 & $1.983 \pm 0.328$ & $\mathrm{I} \cdot 80 \mathrm{I} \pm 0.094$ \\
\hline & & & 2 & $2 \cdot 003 \pm 0.269$ & $I \cdot 784 \pm 0.096$ \\
\hline & Pear & Heterologous & $\mathbf{I}$ & $4.203 \pm 0.295$ & $\mathrm{I} 2 \cdot 535 \pm 2 \cdot 482$ \\
\hline & & & 2 & $4 \cdot 160 \pm 0.293$ & $14 \cdot 140 \pm 2 \cdot 781$ \\
\hline \multirow[t]{2}{*}{ P. morsprunorum $\left(\mathrm{Sm}^{\mathrm{r}}\right)$} & Cherry & Homologous & I & $1.978 \pm 0.293$ & $I \cdot 746 \pm 0.088$ \\
\hline & Pear & Heterologous & 1 & $4.198 \pm 0.323$ & $13 \cdot 480 \pm 3.112$ \\
\hline \multirow[t]{8}{*}{ P. phaseolicola $\left(\mathrm{Sm}^{\mathrm{s}}\right)$} & Bean & Homologous & I & $1 \cdot 276 \pm 0 \cdot 320$ & $I \cdot 864 \pm 0 \cdot 104$ \\
\hline & & & 2 & $1 \cdot 203 \pm 0.311$ & $r \cdot 939 \pm 0.096$ \\
\hline & & & 3 & $I \cdot 444 \pm 0.278$ & $1 \cdot 877 \pm 0.088$ \\
\hline & Tomato & Heterologous & I & $4.483 \pm 0.311$ & $10 \cdot 725 \pm 1 \cdot 750$ \\
\hline & & & 2 & $4.513 \pm 0.288$ & $10 \cdot 550 \pm 2 \cdot 277$ \\
\hline & & & 3 & $4.539 \pm 0.275$ & $11 \cdot 485 \pm 2 \cdot 300$ \\
\hline & Cucumber & Heterologous & I & $4.788 \pm 0.281$ & $10 \cdot 702 \pm 2 \cdot 156$ \\
\hline & Tobacco & Heterologous & I & $4.764 \pm 0.307$ & $11 \cdot 100 \pm 2 \cdot 204$ \\
\hline \multirow[t]{2}{*}{ P. phaseolicola $\left(\mathrm{Sm}^{\mathrm{r}}\right)$} & Bean & Homologous & 1 & $I \cdot 398 \pm 0 \cdot 270$ & $1 \cdot 848 \pm 0.093$ \\
\hline & Tomato & Heterologous & 1 & $4 \cdot 496 \pm 0.300$ & $10.254 \pm 2.058$ \\
\hline \multirow[t]{8}{*}{ P. syringae $\left(\mathrm{Sm}^{8}\right)$} & Pear & Homologous & I & $2.048 \pm 0.304$ & I $\cdot 724 \pm 0.084$ \\
\hline & & & 2 & $2.091 \pm 0.317$ & $I \cdot 739 \pm 0.096$ \\
\hline & Cherry & Heterologous & $\mathbf{I}$ & $3.849 \pm 0.312$ & $8 \cdot 723 \pm I \cdot 665$ \\
\hline & & & 2 & $3.876 \pm 0.328$ & $9 \cdot 460 \pm I \cdot 8 \mathrm{II}$ \\
\hline & Bean & Heterologous & I & $4.072 \pm 0.311$ & $8 \cdot 852 \pm 1 \cdot 444$ \\
\hline & Cucumber & Heterologous & I & $4.584 \pm 0.302$ & $9.951 \pm 1.712$ \\
\hline & Tomato & Heterologous & I & $4 \cdot 130 \pm 0 \cdot 291$ & $8 \cdot 051 \pm 2 \cdot 132$ \\
\hline & Tobacco & Heterologous & $\mathbf{I}$ & $4.551 \pm 0.324$ & $9 \cdot 262 \pm 2 \cdot 144$ \\
\hline \multirow[t]{2}{*}{ P. syringae $\left(\mathrm{Sm}^{\mathrm{r}}\right)$} & Pear & Homologous & I & $2.075 \pm 0.285$ & $1 \cdot 708 \pm 0.087$ \\
\hline & Cherry & Heterologous & I & $3.819 \pm 0.288$ & $7 \cdot 929 \pm \mathrm{I} \cdot 880$ \\
\hline \multirow[t]{10}{*}{ P. tabaci $\left(\mathrm{Sm}^{\mathrm{s}}\right)$} & Tobacco & Homologous & I & $0.603 \pm 0.271$ & $I \cdot 9 I 4 \pm 0.094$ \\
\hline & & & 2 & $0.602 \pm 0.312$ & $1.838 \pm 0.093$ \\
\hline & & & 3 & $0.779 \pm 0.307$ & $1.937 \pm 0.078$ \\
\hline & & & 4 & $0.843 \pm 0.272$ & $I .900 \pm 0.077$ \\
\hline & Cucumber & Heterologous & I & $4.584 \pm 0.272$ & $8 \cdot 127 \pm 1 \cdot 249$ \\
\hline & & & 2 & $4.636 \pm 0.311$ & $9 \cdot 105 \pm 1 \cdot 810$ \\
\hline & & & 3 & $4.622 \pm 0.317$ & $7 \cdot 801 \pm 1.692$ \\
\hline & Bean & Heterologous & I & $4 \cdot 433 \pm 0 \cdot 297$ & $8 \cdot 910 \pm 2.002$ \\
\hline & & & 2 & $4 \cdot 501 \pm 0.297$ & $9 \cdot 127 \pm 1 \cdot 898$ \\
\hline & Tomato & Heterologous & I & $4.314 \pm 0.302$ & $8 \cdot 24 I \pm I \cdot 3 I 4$ \\
\hline \multirow[t]{3}{*}{ P. tabaci $\left(\mathrm{Sm}^{\mathrm{r}}\right)$} & Tobacco & Homologous & $\mathbf{I}$ & $0.634 \pm 0.281$ & $2.015 \pm 0.078$ \\
\hline & & & 2 & $0.770 \pm 0.276$ & $I \cdot 956 \pm 0.082$ \\
\hline & Cucumber & Heterologous & I & $4 \cdot 606 \pm 0 \cdot 288$ & $8 \cdot 543 \pm r \cdot 928$ \\
\hline \multirow[t]{8}{*}{ P. tomato $\left(\mathrm{Sm}^{\mathrm{s}}\right)$} & Tomato & Homologous & I & $1 \cdot 936 \pm 0.325$ & $I \cdot 803 \pm 0.09 I$ \\
\hline & & & 2 & $1.856 \pm 0.295$ & $I \cdot 754 \pm 0.094$ \\
\hline & & & 3 & $\mathrm{I} \cdot 880 \pm 0 \cdot 279$ & $1 \cdot 778 \pm 0.096$ \\
\hline & Bean & Heterologous & I & $4.584 \pm 0.316$ & $12 \cdot 174 \pm 2 \cdot 445$ \\
\hline & & & 2 & $4.529 \pm 0.306$ & $13.122 \pm 2.567$ \\
\hline & & & 3 & $4.545 \pm 0.321$ & $12 \cdot 270 \pm 2 \cdot 223$ \\
\hline & Cucumber & Heterologous & I & $4.729 \pm 0.278$ & I $2 \cdot 702 \pm 2 \cdot 385$ \\
\hline & Tobacco & Heterologous & I & $4 \cdot 692 \pm 0.290$ & $14 \cdot 105 \pm 2 \cdot 630$ \\
\hline \multirow[t]{2}{*}{ P. tomato $\left(\mathrm{Sm}^{\mathrm{r}}\right)$} & Tomato & Homologous & I & $1.950 \pm 0.301$ & $I \cdot 746 \pm 0.085$ \\
\hline & Bean & Heterologous & I & $4.546 \pm 0.329$ & $12 \cdot 370 \pm 2 \cdot 185$ \\
\hline
\end{tabular}



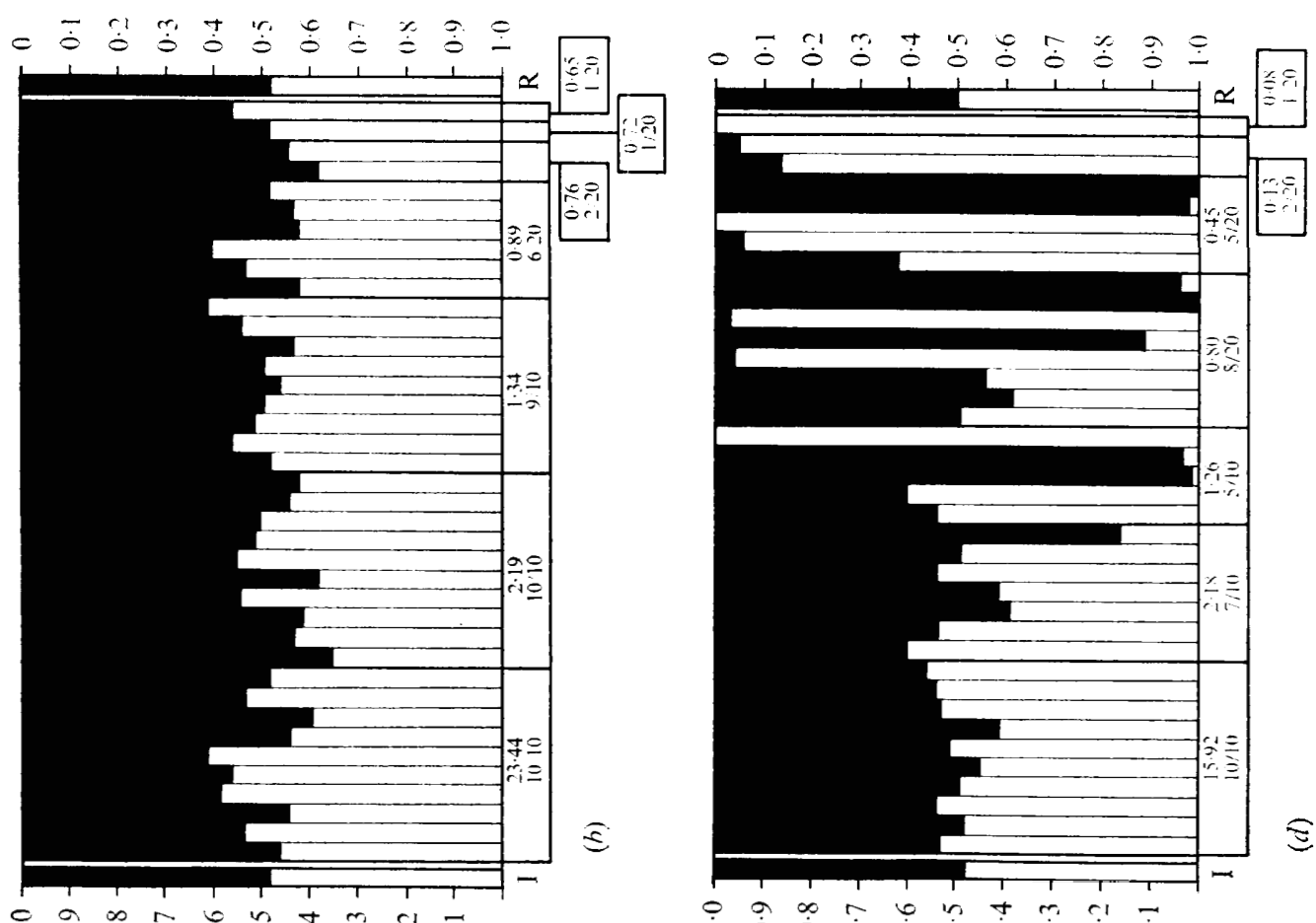

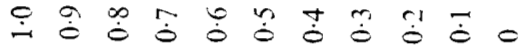
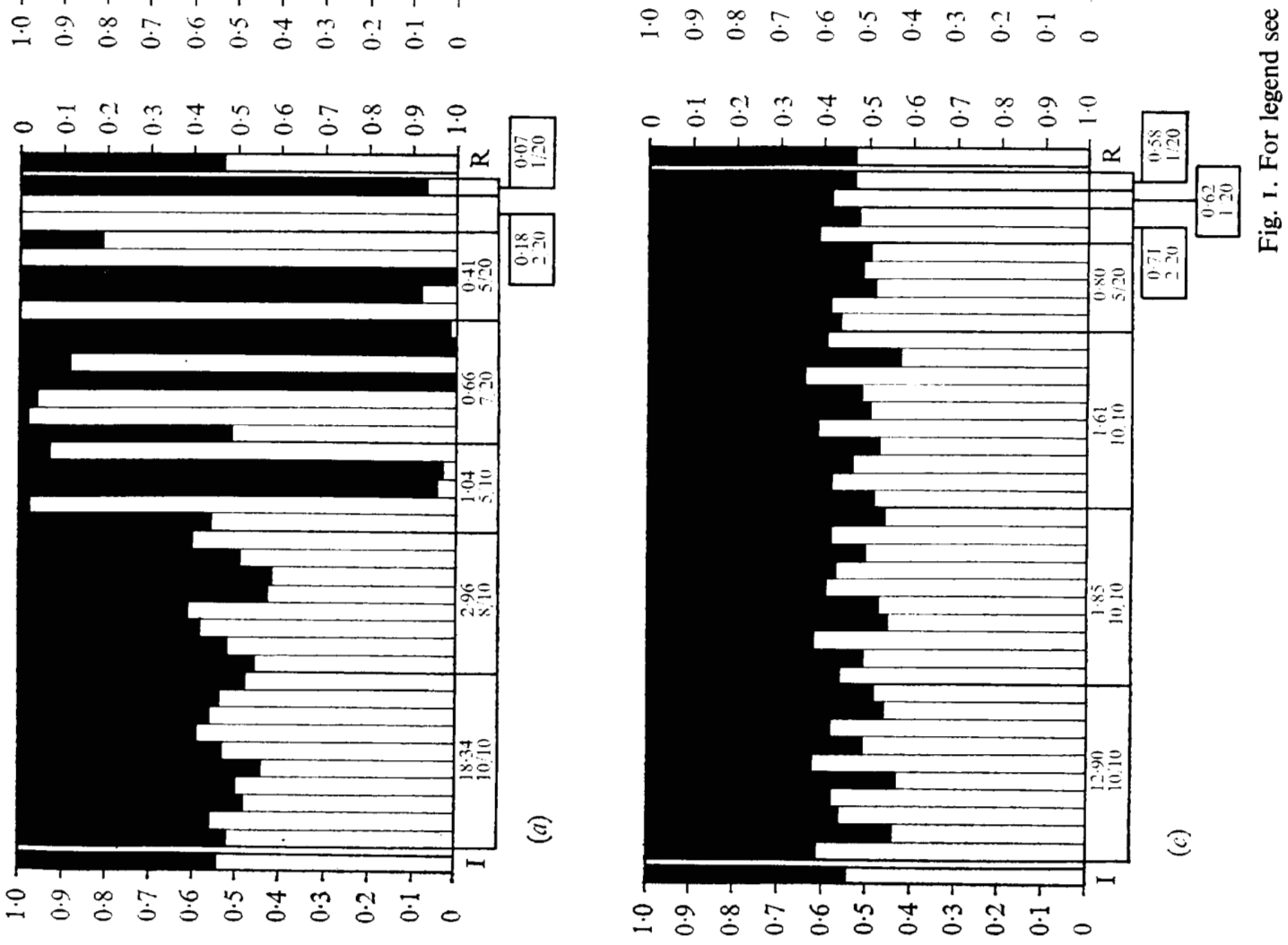
the relative infectivity of different bacteria for each host could not be obtained by direct comparison of the respective ED 50 values, because of the broad differences in the corresponding values of $b$ (Table I). Thus, for the reasons given in the Discussion, differences in the relative infectivity of homologous and heterologous bacteria were more marked at the lower doses of inoculum.

Probit slopes for infectivity of different bacteria for each plant species were never significantly greater than 2 in the homologous combinations and invariably much greater than 2 in the heterologous ones, suggesting that inoculated bacteria were acting independently in the former combination type and co-operating in the latter (Peto, I953; Meynell \& Stocker, 1957).

Cucumber and tobacco plants gave a fairly uniform susceptible response to Pseudomonas lachrymans $(b>\mathrm{I} \cdot 872)$ and $P$. tabaci $(b>\mathrm{I} \cdot 838)$, respectively, but progressively increasing amounts of heterogeneity in susceptibility to the homologous pathogens were present in bean, cherry, tomato and pear plants. The degree to which individual plants differed in their resistance to heterologous bacteria appeared to be correlated with the identity of the bacterium involved, rather than to the botanical identity of the plant itself. In this respect, more uniform responses were induced by $P$. morsprunorum, $P$. lachrymans and $P$. tomato $(b>\mathrm{I} 2)$ than by $P$. tabaci and $P$. syringae $(b<\mathrm{I} 0)$, with $P$. phaseolicola ranging between the two groups.

Mixed inoculation experiments. Fig. I to 3 show the composition of bacterial populations isolated from the plants that responded to inoculation with a mixture of $\mathrm{Sm}^{\mathrm{s}}$ and $\mathrm{Sm}^{\mathrm{r}}$ variants of the same pathogen. Plants responding after inoculation with more than I ED 50 of the mixture were generally found to comprise both variants in approximately the same proportion as they were in the inoculum. Only a small number of plants given few ED 50s of a mixture of the $\mathrm{Sm}^{\mathrm{s}}$ and $\mathrm{Sm}^{\mathrm{r}}$ variants of the homologous pathogen contained a predominance of one variant. Plants challenged with I ED 50 or less yielded different results, depending on the type of plant/pathogen combination studied. In the heterologous combinations, the composition of bacterial populations was always similar to that of the challenge dose, but in the homologous ones a single variant was generally present alone or with a small proportion of the other variant. When all plants responding to inoculation in each experiment were considered together, the overall frequency of isolation of each variant proved to be approximately equal to the proportion in which the same variant was present in the inoculum, thus confirming that no detectable difference existed between the infectivity of the $\mathrm{Sm}^{\mathrm{s}}$ and $\mathrm{Sm}^{\mathrm{r}}$ variants of the same pathogen.

The observed rates of occurrence of $\mathrm{Sm}^{\mathrm{s}}$ and $\mathrm{Sm}^{\mathrm{r}}$ variants in plants responding to inoculation with different doses of the homologous pathogen were compatible with the predictions of the hypothesis of independent action, but not with those of the hypothesis of co-operative action (Meynell \& Stocker, I957), and the reverse was true of the plants given different doses of a heterologous pathogen. This supports the conclusion, reported above, of the experiments in which the slope of the log dose/probit response curve was measured.

Fig. 1. Proportion of a streptomycin-sensitive clone (shown in white) and a streptomycin-resistant clone (shown in black) of Pseudomonas phaseolicola and $P$. tomato in the leaves of bean and tomato plants responding to inoculation with graded doses of a mixture of the two variants. (a) Pseudomonas phaseolicola on bean (homologous combination); (b) P. tomato on bean (heterologous); (c) $P$. phaseolicola on tomato (heterologous); (d) $P$. tomato on tomato (homologous). Each column represents one leaf. The column at the extreme left shows the proportions of the two variants in the inoculum (I) and that at the extreme right their overall rate of recovery $(R)$ in the plants responding. The doses of inoculum (expressed as number of ED 505 ) and the ratio of responding to inoculated plants are also indicated at the bottom of each graph. 

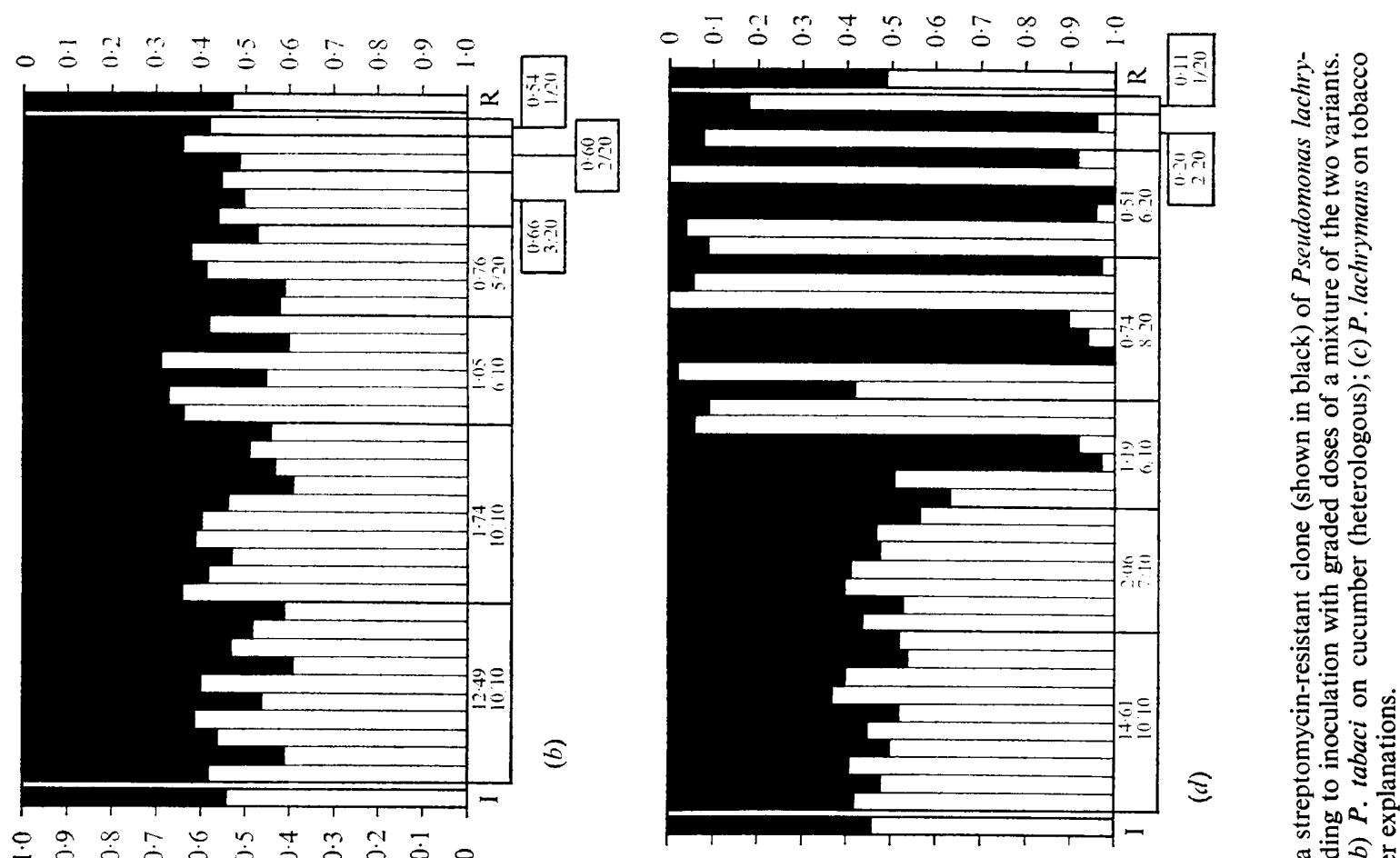

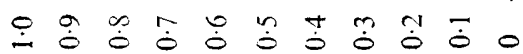

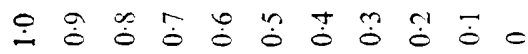

원

宁 余豆

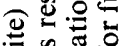

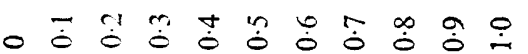

- $\dot{0} \ddot{0} \ddot{0} \dot{0} \ddot{0} \dot{0} \check{0} \stackrel{\infty}{0} \dot{0} \dot{0}$

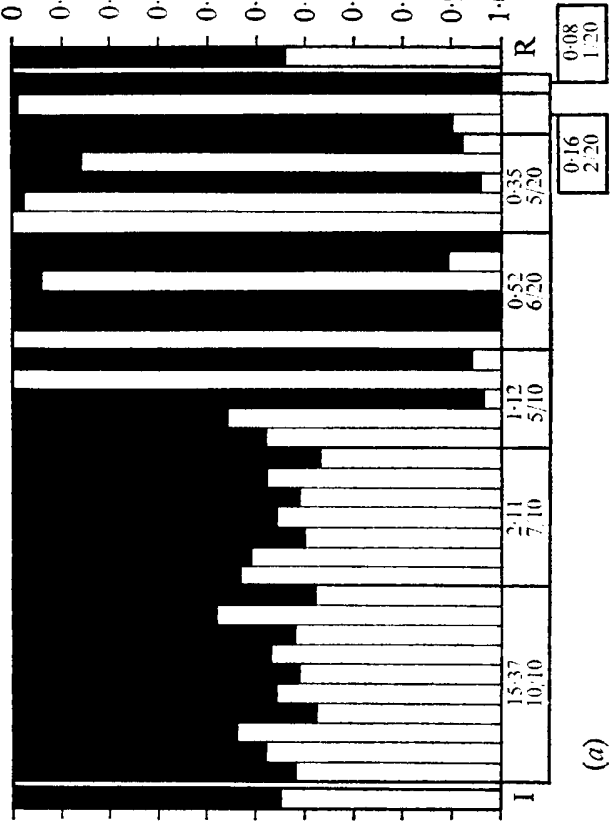

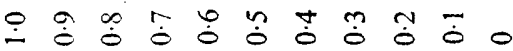

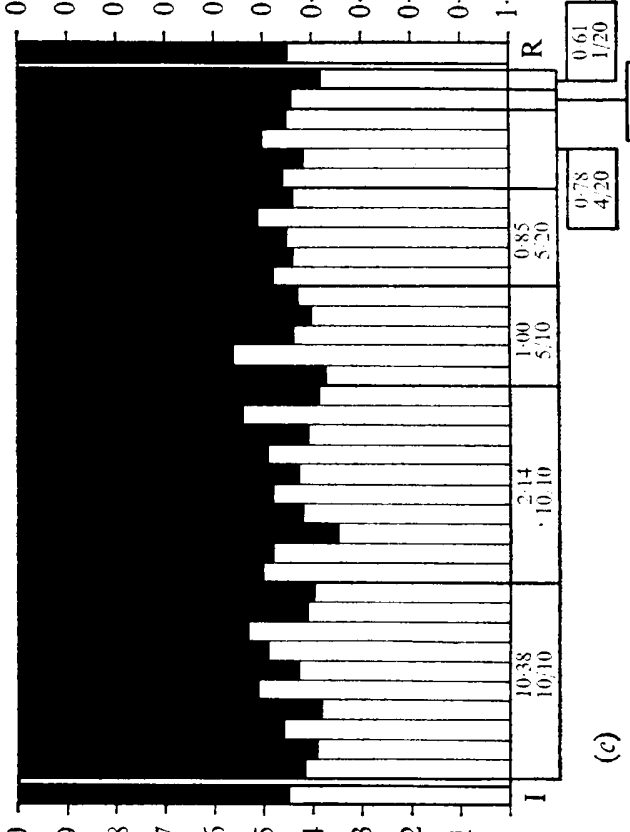

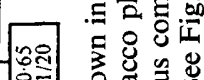

靬气

ज용

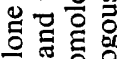

\&

¿

ฮ

记

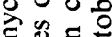

छิ

응

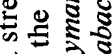

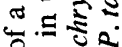

$\frac{2}{2} \frac{8}{2}$

है

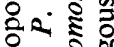

둥

i

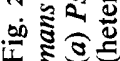

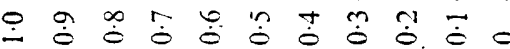



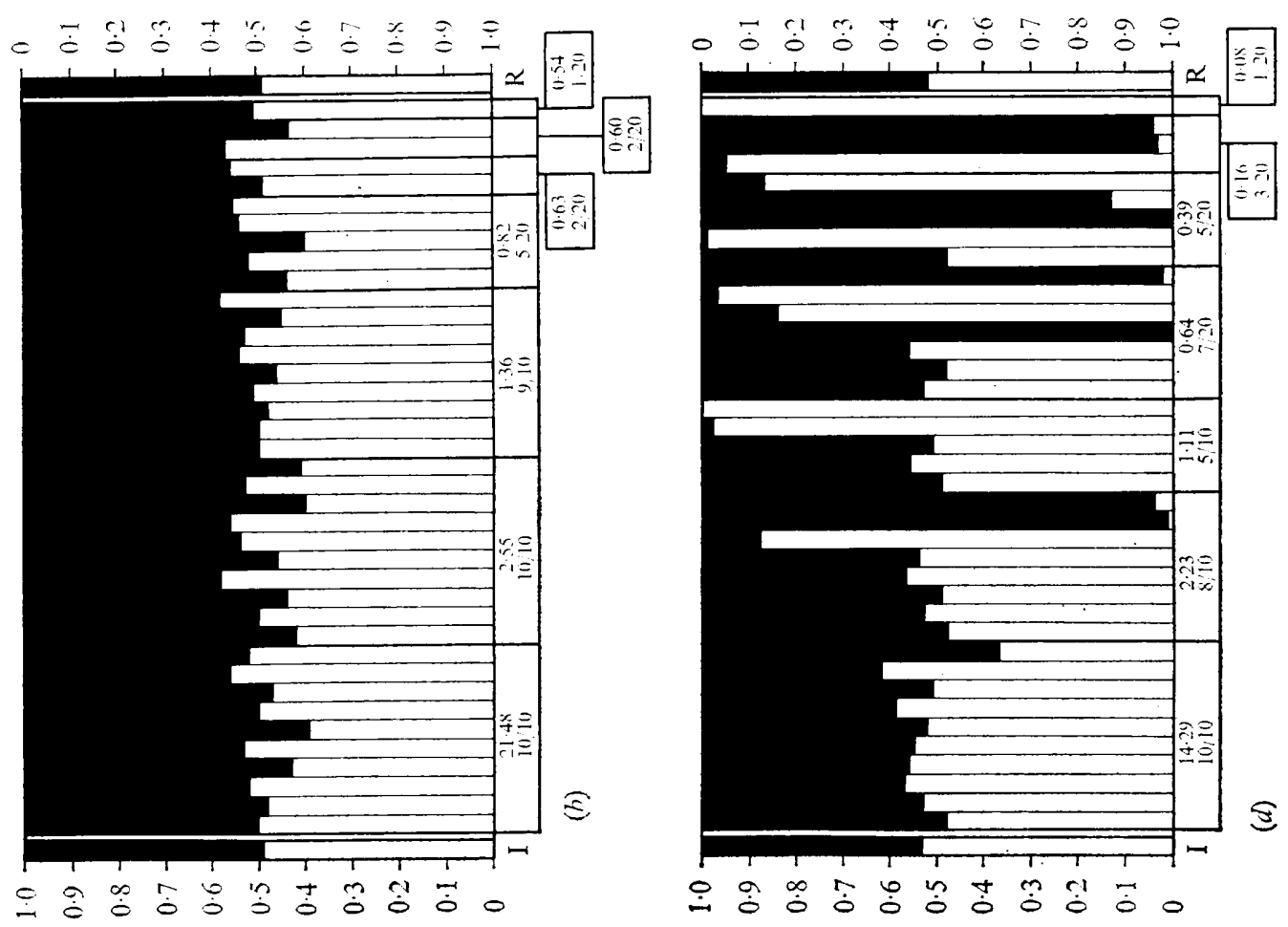

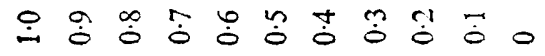
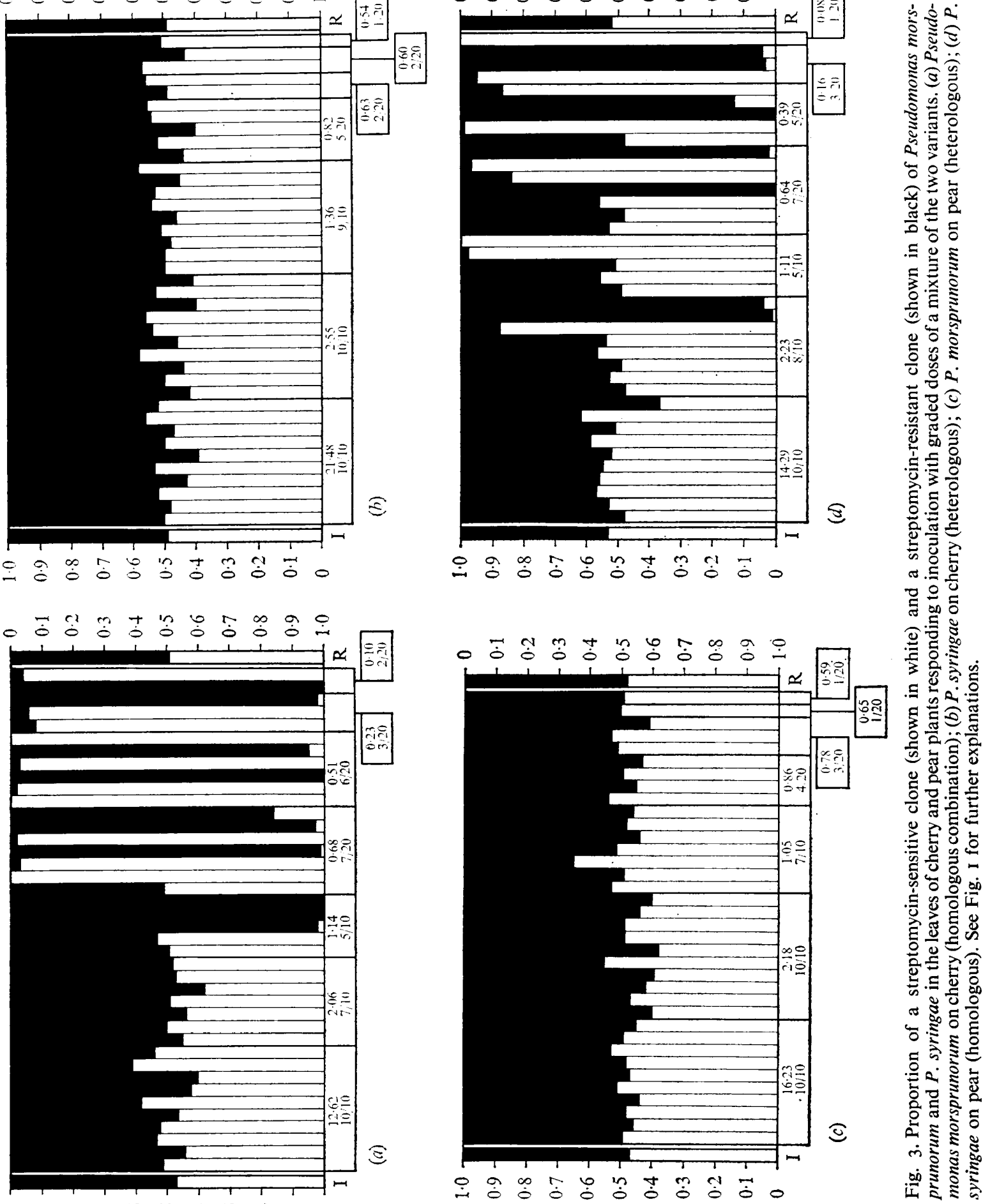

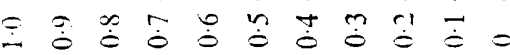




\section{I)ISCUSSION}

The results of infectivity titration and mixed inoculation experiments performed in this study combine to show that the aetiology of response of plants to challenge by homologous and heterologous pathogens is substantially different. The outcome of infection of any of the six plant species tested with the selected homologous pseudomonad pathogen always fulfilled the expectations of a system to which the hypothesis of independent action was applicable. Since the hypothesis is stochastic in nature, in such systems the host response may be produced by the progeny of only one of the inoculated bacteria. Thus, the findings of this study corroborate the few previous reports of a single phytopathogenic bacterium being sufficient to infect its homologous host (Hildebrand, I937; Thyr, 1968). Infectious units of Agrobacterium tumefaciens may consist of single bacteria (Hildebrand, 1942; Lippincott \& Heberlein, 1965; Manigault \& Beaud, 1967), but the diversity of the mechanism of pathogenesis involved therein sets the relationship between inoculated bacteria in that system quite apart, conceptually at least, from that in most other natural plant/pathogen combinations. In contrast with their behaviour in their homologous hosts, single bacteria of any of the six pathogenic pseudomonads used in this study proved inherently incapable of infecting heterologous hosts. Although the 'individual effective dose' necessary for induction of symptoms by any of the heterologous pathogens varied to some extent from plant to plant, as indicated by the observed probit slopes, the values of the latter were always much in excess of 2, indicating that plant responses resulted from the joint action of several of the inoculated bacteria. This is consistent with the large existing body of evidence which indicates that symptoms are only observed in heterologous combinations following introduction of heavy doses of inoculum into the plant (Logan, 1960; Klement \& Goodman, 1967a; Hildebrand \& Riddle, 197r).

Why phytopathogenic bacteria act independently in their homologous hosts but cooperate to induce response in the heterologous ones has to be left open to speculation at the present time. Evidently, within the tissues of any plant given the same number of ED 50 s of either a homologous or a heterologous pathogen, interaction between inoculated bacteria is more likely to occur in the latter case, in which the resulting concentration of bacteria in the tissues is higher. The production of typical disease symptoms in homologous combinations is strictly a function of bacterial multiplication in vivo, and attainment of certain population thresholds is a prerequisite for symptom production in such systems (see Ercolani, $1968 \mathrm{~b}$ ). In heterologous combinations, symptoms of the so-called hypersensitive type appear after a period of predictable and comparatively short duration even if the bacteria are killed as early as 2 or $3 \mathrm{~h}$ after inoculation (Klement \& Goodman, $1967 b$; Klement, 197I). Although the mechanism of its induction is not clear, hypersensitivity in its present acceptance appears to be primarily a host reaction triggered by the bacteria during a short "induction period' immediately following inoculation (Klement, 197I). Since co-operation in vivo is characteristic, in animals at least, of inanimate agents like drug molecules (Meynell, 1957), the interaction between inoculated heterologous bacteria in plant tissues might simply reflect the joint cumulative effect of some bacterial component on the plant. Sequeira \& Ainslie (1969), Ercolani (1970), Sleesman, Perley \& Hoitink (1970) and Gardner \& Kado (1972) have reported on the possible occurrence of such components in the surface layers of phytopathogenic bacteria.

When very high numbers of bacteria are introduced into a host plant, homologous pathogens will also be likely to interact and to some extent co-operate to give infection. In this case, however, co-operation would be of a somewhat different kind since it would depend 
on the resultant overloading of the plant tissues with an overwhelming dose, and not on the inherent phytopathogenic apparatus of the micro-organisms involved. In this respect, it would seem appropriate that future studies on this subject include varieties of the same plant species, whose expected response to inoculation with the same pathogen would be either of the compatible or of the hypersensitive type.

Although dose/response relationships for all systems included in this study invariably assumed a linear form when they were plotted on a metameric $\log$ dose $/ \log (-\ln$ response) scale, the slope of individual plots differed depending on the type of plant/pathogen combination involved. In the homologous combinations, probit slopes $b \simeq 2$ were transformed into Weibull slopes of approximately I, indicating (i) that the mean probability, $P$, per inoculated bacterium of multiplying in vivo to induce response was invariant to the average concentration, $d$, of bacterial cells in the standard inoculum received by the plants (Peto, 1953; Armitage, 1959), and (ii) that the underlying relationship between the proportion of uninfected plants, $Q$, and the bacterial concentration, $d$, was a simple exponential, $Q=e^{-P d}$, with $e$ being the base of natural logarithms (Druett, 1952; Peto, I953). In the heterologous combinations, probit slopes $b \gg 2$ were transformed into Weibull slopes considerably greater than $\mathrm{I}$, thus indicating that $P$ values increase with the average concentration of bacteria in the inoculum dose, $d$.

It therefore appears that the relative infectivity of homologous and heterologous bacteria for any given plant can only be estimated with some approximation by studying dose/ response relationships over a considerably broader range of inoculum doses than has been used customarily in phytobacteriological experiments so far. Although the most appropriate dosage for this kind of titrations is obviously dependent on the inoculum potential (sensu Horsfall, 1932) of different pathogens in the field, from the practical standpoint comparable variations of the dose of inoculum will cause the proportion of responding plants to change more dramatically in heterologous combinations. Also, whenever, as in this study, the definition of the ED 50 or other critical dose is given at the level of individual leaves, variations in leaf size between plants of different species will make comparisons of the infectivity of the same bacterium for different plants difficult.

The occurrence of a minority of one variant along with a majority of the other variant in plants responding to inoculation with I ED 50 or less of the homologous pathogen can probably be explained, in this as in other mixed inoculation experiments (Meynell \& Stocker, 1957; Ercolani, 1967b), by a terminal breakdown of host resistance at a late stage of invasion by the progeny of one cell of the dominant variant. In a few control experiments in which leaves expected to respond to challenge with I ED 50 were sampled at different times up to 2 days before the earliest anticipated date of appearance of symptoms, only one variant was almost invariably found. Where both variants co-existed, their proportion was always close to I: I, suggesting that the leaf in question was abnormally susceptible. As a result of differences in individual host resistance, the observed rate of occurrence of both variants together is known to be greater than expected in plants responding to inoculation with low doses and smaller than expected in those given high doses (Meynell \& Stocker, 1957). In this respect it might be significant that tomato and pear plants, which appeared to give a somewhat heterogeneous response to their homologous pathogens as indicated by $b$ values of I.746 to I. 803 and I. 708 to I $\cdot 739$ for $P$. tomato and $P$. syringae respectively, were also those which yielded the highest number of leaves containing either a single variant after inoculation with more than I ED50, or both variants after inoculation with I ED50 or less. However, these results should be considered with caution, because the amount of heterogeneity in the resistance of the plant material was not very great. 
For practical purposes, it is usually taken as a matter of course that homologous and heterologous pathogens be thus defined with respect to the plant from which they were isolated originally. However, these assumptions might cause some degree of confusion in laboratory work if a bacterium happened to be isolated from a hypersensitive lesion developed on a non-host plant under abnormal ecological conditions in the field. The results of this study suggest that the homologous or heterologous nature of plant/pathogen interactions may in fact be recognized by simply determining whether challenging bacteria are acting independently or co-operating during growth in vivo. Even those modifications of the basic mechanism of invasion of plant tissue by homologous bacteria, which may occur when the inoculum dose is raised above I ED 50 (Ercolani, 1972), will not affect the discriminative power of the techniques used in this study to recognize different types of plant/pathogen combination.

A part of this work was presented at the First International Congress of Plant Pathology, London (July, 1968), with financial support from a grant from the National Research Council of Italy.

\section{REFERENCES}

Armitage, P. (1959). An examination of some experimental cancer data in the light of the one-hit theory of infectivity titrations. Journal of the National Cancer Institute 23, $1313-1330$.

Crosse, J. E. (1959). Bacterial canker of stone fruits. IV. Investigation of a method for measuring the inoculum potential of cherry trees. Annals of Applied Biology 47, 306-31 7.

DruetT, H. A. (1952). Bacterial invasion. Nature, London 170, 288.

Ercolani, G. L. (1967a). Bacterial canker of tomato. I. Analysis of some factors affecting the response of tomato to Corynebacterium michiganense (E. F. Sm.) Jens. Phytopathologia Mediterranea 6, 19-29.

ERCOLANI, G. L. $(1967 b)$. Bacterial canker of tomato. II. Interpretation of the aetiology of the quantal response of tomato to Corynebacterium michiganense (E. F. Sm.) Jens. by the hypothesis of independent action. Phytopathologia Mediterranea 6, 30-40.

Ercolani, G. L. (1968a). Growth of bacteria in plant tissue. In Abstracts of Papers, First International Congress of Plant Pathology, p. 55. London: International Society for Plant Pathology.

Ercolani, G. L. (1968b). Schizomycetes. In Manuale di Patologia Vegetale, vol. 3, pp. I-456. Edited by G. Goidanich. Bologna: Edizioni Agricole.

ErcolanI, G. L. (1970). Bacterial canker of tomato. IV. The interaction between virulent and avirulent strains of Corynebacterium michiganense (E. F. Sm.) Jens. in vivo. Phytopathologia Mediterranea 9, I 5 I-I 59.

Ercolani, G. L. (1972). Dynamics of infection by Pseudomonas phaseolicola in partially resistant populations of bean. Phytopathology 62, 756.

Ercolani, G. L. \& Crosse, J. E. (1966). The growth of Pseudomonas phaseolicola and related plant pathogens in vivo. Journal of General Microbiology 45, 429-439.

Finney, D. J. (1971). Probit Analysis, 3rd edn. Cambridge University Press.

GARDNER, J. M. \& KADO, C. I. (1972). Induction of the hypersensitive reaction in tobacco with specific high-molecular weight substances derived from the osmotic shock fluid of Erwinia rubrifaciens. Phytopathology 62, 759.

Hildebrand, E. M. (1937). Infectivity of the fire-blight organism. Phytopathology 27, 850-852.

Hildebrand, E. M. (1942). A micrurgical study of crown gall infection in tomato. Journal of Agricultural Research 65, 45-59.

Hildebrand, D. C. \& Riddle, B. (I971). Influence of environmental conditions on reactions induced by infiltration of bacteria into plant leaves. Hilgardia 4r, 33-43.

Hoagland, D. R. \& SNYder, W. C. (I933). Nutrition of strawberry plant under controlled conditions. (A) Effects of deficiencies of boron and certain other elements. (B) Susceptibility to injury from sodium salts. Proceedings of the American Society for Horticultural Science 30, 288-294.

Horsfall, J. G. (1932). Dusting tomato seed with copper sulfate monohydrate for combating damping-off. New York State Agricultural Experiment Station Technical Bulletin, no. 198, 34 pp. 
KLement, Z. (1971). Development of the hypersensitivity reaction induced by plant pathogenic bacteria. In Proceedings of the Third International Conference on Plant Pathogenic Bacteria, pp. 157-164. Edited by H. P. Maas Geesteranus. Wageningen: Centre for Agricultural Publishing and Documentation.

Klement, Z., Farkas, G. L. \& Lovrekovich, L. (I964). Hypersensitive reaction induced by phytopathogenic bacteria in the tobacco leaf. Phytopathology 54, 474-477.

Klement, Z. \& Goodman, R. N. (1967a). The hypersensitive reaction to infection by bacterial plant pathogens. Annual Review of Phytopathology 5, 17-44.

KLement, Z. \& Goodman, R. N. $(1967 b)$. The role of the living bacterial cell and induction time in the hypersensitive reaction of the tobacco plant. Phytopathology 57, 322-323.

Klement, Z. \& Lovrekovich, L. (I961). Defence reactions induced by phytopathogenic bacteria in bean pods. Phytopathologische Zeitschrift 41, 21 7-227.

Klement, Z. \& Lovrekovich, L. (1962). Studies on host-parasite relations in bean pods infected with bacteria. Phytopathologische Zeitschrift 45, 8I-88.

Lederberg, J. \& Lederberg, E. M. (1952). Replica plating and indirect selection of bacterial mutants. Journal of Bacteriology 63, 399-406.

Lelliott, R. A., Billing, E. \& Hayward, A. C. (1966). A determinative scheme for the fluorescent plant pathogenic pseudomonads. Journal of Applied Bacteriology 29, 470-489.

Lippincott, J. A. \& Heberlein, G. T. (1965). The quantitative determination of the infectivity of Agrobacterium tumefaciens. American Journal of Botany 52, 856-863.

Logan, C. (1960). Host specificity of two Xanthomonas species. Nature, London 188, 479-480.

Manigault, P. \& Beaud, G. (1967). Expression de l'efficacité de la bactérie Agrobacterium tumefaciens (Smith et Town) Conn dans l'induction tumorale (Datura stramonium L.). Annales de l'Institut Pasteur II2, 445-457.

Meynell, G. G. (1957). Inherently low precision of infectivity titrations using a quantal response. Biometrics I3, I49-163.

Meynell, G. G. \& Meynell, E. (1970). Theory and Practice in Experimental Bacteriology, 2nd edn. Cambı idge University Press.

Meynell, G. G. \& Stocker, B. A. D. ( I957). Some hypotheses on the aetiology of fatal infections in partially resistant hosts and their application to mice challenged with Salmonella paratyphi-B or Salmonella typhimurium by intraperitoneal injection. Journal of General Microbiology 16, 38-58.

Pérombelon, M. C. M. (I97I). A quantitative method for assessing virulence of Erwinia carotovora var. carotovora and E. carotovora var. atroseptica and susceptibility to rotting of potato tuber tissue. In Proceedings of the Third International Conference on Plant Pathogenic Bacteria, pp. 299-303. Edited by H. P. Maas Geesteranus. Wageningen: Centre for Agricultural Publishing and Documentation.

Peto, S. (1953). A dose-response equation for the invasion of micro-organisms. Biometrics 9, 320-335.

Seligman, S. J. \& Mickey, M. R. (I964). Estimation of the number of infectious bacterial or viral particles by the dilution method. Journal of Bacteriology 88, $3 \mathrm{I}-36$.

Sequeira, L. \& Ainslie, V. (1969). Bacterlal cell-free preparations that induce or prevent the hypersensitive reaction in tobacco. In Abstracts of Papers, Ninth International Botanical Congress, p. I95. Seattle: Botanical Society of America.

Shortley, G. \& Wilkins, J. R. (1965). Independent-action and birth-death models in experimental microbiology. Bacteriological Reviews 29, I02-I4I.

Sleesman, H. C., Perley, J. E. \& Hoitink, H. A. J. (1970). Susceptible and hypersensitive reactions in tobacco and their prevention by cell-free extracts of Pseudomonas tabaci and Pseudomonas glycinea. Phytopathology 60, I 314.

Thyr, B. D. (1968). Bacterial canker of tomato: inoculum level needed for infection. Plant Disease Reporter $52,74 I-743$. 